\title{
Analyses of FGFR3 and PIK3CA mutations in neuroblastomas and the effects of the corresponding inhibitors on neuroblastoma cell lines
}

\author{
OURANIA N. KOSTOPOULOU ${ }^{1 *}$, STEFAN HOLZHAUSER $^{1 *}$, BIRTHE K.A. LANGE $^{1}$, ANNA OHMAYER ${ }^{1}$, \\ TEODORA ANDONOVA $^{2}$, CINZIA BERSANI $^{1}$, MALIN WICKSTRÖM $^{2 * *}$ and TINA DALIANIS ${ }^{1 * *}$
}

Departments of ${ }^{1}$ Oncology-Pathology, and ${ }^{2}$ Women's and Children's Health, Karolinska Institutet, 17174 Stockholm, Sweden

Received June 15, 2019; Accepted September 10, 2019

DOI: 10.3892/ijo.2019.4896

\begin{abstract}
Fibroblast growth factor receptor (FGFR)3 and phosphatidylinositol-4,5-bisphosphate 3-kinase, catalytic subunit alpha (PIK3CA) mutations are found in various types of cancer, such as urinary bladder cancer, human papillomavirus-positive tonsillar and base of the tongue squamous cell carcinoma, breast cancer and some childhood sarcomas. Several drugs can target these genes, some of which have been used for the treatment of urinary bladder cancer. Much less is known about childhood cancer. For this reason, the present study investigated the presence of such mutations in neuroblastomas (NBs) and tested NB cell lines for sensitivity to FGFR and phosphoinositide 3-kinase (PI3K) inhibitors. In total, $29 \mathrm{NBs}$ were examined for the presence of the three most common FGFR3 and PIK3CA mutations using a competitive allele-specific TaqMan PCR (CAST-PCR). Furthermore, the SK-N-AS, SK-N-BE(2)-C, SK-N-DZ, SK-N-FI and SK-N-SH NB cell lines (where SK-N-DZ had a deletion of PIK3C2G, none had FGFR mutations according to the Cancer Program's Dependency Map, but some were chemoresistant), were tested for sensitivity to FGFR (AZD4547) and PI3K (BEZ235 and BKM120) inhibitors by viability, cytotoxicity, apoptosis and proliferation assays. CAST-PCR detected one FGFR3 mutation in $1 / 29$ NBs. Following treatment with FGFR and
\end{abstract}

Correspondence to: Professor Tina Dalianis, Department of Oncology-Pathology, Karolinska Institutet, Visionsgatan 4, 17174 Stockholm, Sweden

E-mail: tina.dalianis@ki.se

Dr Malin Wickström, Department of Women's and Children's Health, Karolinska Institutet, Visionsgatan 4, 17174 Stockholm, Sweden

E-mail: malin.wickstrom@ki.se

\section{${ }^{*, * * *}$ Contributed equally}

Key words: neuroblastoma, fibroblast growth factor receptor 3 mutations, phosphatidylinositol-4,5-bisphosphate 3-kinase, catalytic subunit alpha mutations, childhood cancer, neuroblastoma, PI3K inhibitors, fibroblast growth factor receptor inhibitors
PI3K inhibitors, a decrease in viability and proliferation was observed in the majority, but not all, the cell lines. Following combination treatment with both drugs, the sensitivity of all cell lines was increased. On the whole, the findings of this study demonstrate that FGFR3 and PIK3CA mutations are uncommon in patients with NB. However, certain NB cell lines are rather sensitive to both FGFR and PI3K inhibitors alone, and even more so when the different drugs are used in combination.

\section{Introduction}

Fibroblast growth factor receptors (FGFRs) are a family of tyrosine kinase receptors that are deregulated in several types of cancer, leading to alterations in cell proliferation, migration, epithelial-mesenchymal transition, invasion, survival and angiogenesis (1-6). For example, the interaction of FGFR3 with its specific ligands leads to the phosphorylation of the receptor, and the activation of pathways, such as the mitogen-activated protein kinase (MAPK) and the phosphoinositide 3-kinase/protein kinase B (PI3K/AKT) pathways. Aberrations in the FGFR3 gene have been shown to contribute to tumor development (1). Common alterations include FGFR3 point mutations, gene amplification and translocations, the latter resulting in different fusion genes frequently occurring in bladder cancer, but also in breast cancer, lung cancer, glioblastoma and human papillomavirus positive tonsillar and base of the tongue squamous cell carcinoma (1-6). In addition, early-phase clinical trials with FGFR-directed targeted therapies for glioblastoma multiforme, transitional cell carcinoma and multiple myeloma carrying mutated FGFR3 (NCT01975701, NCT02278978, NCT02401542 and NCT02052778) have been conducted, indicating the potential of such therapies in other types of cancer.

Knowledge on the role of the FGFR protein family in childhood cancer remains limited, and novel therapeutic targets would be helpful. In a previous study, FGFR4 mutations were detected in 7/94 (7.5\%) cases of primary human rhabdomyosarcomas (6). Another study on ependymomas and pilocytic astrocytomas revealed an increased FGFRI and FGFR3 expression in aggressive ependymomas (7). RNA sequencing in glioblastomas has revealed an overexpression of 
the tumorigenic FGFR3-TACC3 fusion gene, enhanced proliferation and tumor progression (8). Furthermore, the FGFRI mutation (N546K) and FGFRl locus copy number gain has been reported as a characteristic feature of Ewing sarcoma (9). Thus, an increasing number of studies investigating the role of FGFR deregulation in different types of cancer have revealed an association between receptor overexpression and tumor progression, as well as the potency of a targeted therapy against the FGFR receptor family (1-9). Nonetheless, there is still a gap of information regarding the status of FGFRs in childhood cancer.

There is somewhat more information on the role of the PI3K pathway in childhood cancer. PIK3CA mutations have been reported in pediatric high-grade gliomas, as well as in pediatric diffuse intrinsic pontine gliomas and rhabdomyosarcomas, while in neuroblastomas (NBs), specific constitutional PIK3CA mutations are infrequent (10-14). However, the activation of the $\mathrm{PI} 3 \mathrm{~K} / \mathrm{AKT} / \mathrm{mammalian}$ target of rapamycin (mTOR) signaling axis has been reported to predict a poor prognosis of patients with NB (15). Furthermore, responses to PI3K inhibitors in NB have been examined, and a correlation between $M Y C N$ proto-oncogene, BHLH transcription factor (MYCN) amplification and sensitivity to mTOR kinase inhibitors has been reported (16). More specifically, PI3K/mTOR inhibitors have been shown to induce an enhanced MYCN phosphorylation and proteasomal degradation (16-18). Nevertheless, resistance to single treatment with PI3K inhibitors has also been reported (19). It could potentially be useful to obtain more information on the sensitivity of different childhood tumors to FGFR and PI3K inhibitors. The present study focused on NB, a childhood cancer of the peripheral nervous system that is the most common and most lethal tumor affecting infants $(20,21)$. A number of NB cell lines with different clinical characteristics, including MYCN amplification and 11q deletion, were therefore tested for their sensitivity to FGFR (AZD4547) and PI3K (BEZ235 and BKM120) inhibitors alone, or AZD4547 and BEZ235 in combination. In addition, a limited number of NBs were screened for the presence of the most commonly occurring FGFR 3 and PIK3CA mutations.

\section{Materials and methods}

Patients and tumor characteristics. NBs from patients aged 0-11.5 years, diagnosed between 1991 and 2008 at the Karolinska University Hospital (Stockholm, Sweden) were analyzed for the most common FGFR3 and PIK3CA mutations (see below); the details of the patient tumor characteristics have been previously described (22). The study was performed according to approval no. 2009/1369-31/1, 2007/1253-31/3 and 2003/736 from the Ethics Committee of the Karolinska Institutet. Informed consent for the use of tumor samples in research was provided by the parents/guardians. In accordance with the approval from the Ethics Committee the informed consent was either written or verbal. When verbal or written assent was not obtained the decision was documented in the medical record. Kaplan-Meyer survival curves and gene correlations were created using the R2: Microarray analysis and visualization platform (http://r2.amc.nl). The used cohort Kocak contains gene expression profiles from 649 neuroblastoma tumors generated using 44K oligonucleotide microarrays (23).

Tumor cell lines and culture conditions. For the in vitro experiments, the NB cell lines, SK-N-AS, SK-N-BE(2)-C, SK-N-DZ, SK-N-FI and SK-N-SH, were kindly provided by Professor Per Kogner of the Karolinska Institutet and have been described in a number of previous studies (24-28). All cell line identities were verified by short tandem repeat genetic profiling using the AmpFLSTR Identifiler PCR Amplification kit (Thermo Fisher Scientific, Inc.) in 2016, and the cell lines were used at passages $<25$ following thawing. Furthermore, according to the Cancer Dependency Map (https://depmap.org/portal/), none of the included cell lines had any FGFR3 mutations (Fig. S1), while SK-N-DZ had a frameshift deletion of $P I K 3 C 2 G$, as well as an $M Y C N$ amplification, as was also the case with SK-N-BE(2)-C. The SK-N-BE(2)-C cell line was derived from a previously treated relapsed patient and is known to be chemoresistant (i.e., to doxorubicin) (28). Both the SK-N-DZ and SK-N-AS cells contain an 11q deletion $(29,30)$, and SK-N-FI has a high MDR1 expression (31). The NB cell lines were cultured in RPMI (Thermo Fisher Scientific, Inc.), with 10\% FBS (Thermo Fisher Scientific, Inc.), 1\% L-glutamine, $100 \mathrm{U} / \mathrm{ml}$ penicillin and $100 \mu \mathrm{g} / \mathrm{ml}$ streptomycin (Thermo Fisher Scientific, Inc.). UPCI-SCC-154, a squamous cell carcinoma of the tongue (provided by Susan Gollin, University of Pittsburgh USA) and HPV- UT-SSC-60A, a tonsillar squamous cell carcinoma (obtained from Reidar Grénman, University of Turku, Finland) were cultured in Dulbecco's modified Eagle's medium (Gibco, Thermo Fisher Scientific, Inc.), with $10 \%$ FBS, $1 \%$ L-glutamine, $100 \mathrm{U} / \mathrm{ml}$ of penicillin, and $100 \mu \mathrm{g} / \mathrm{ml}$ streptomycin and used as positive control in the western blots. All cells were maintained at $37^{\circ} \mathrm{C}$ in a humidified incubator with $5 \%$ $\mathrm{CO}_{2}$. The genetic dependency of FGFR3 was analyzed in the Cancer Dependency Map with public data connecting tumor features with tumor dependencies (https://depmap. org/portal).

Competitive allele-specific TaqMan PCR (CAST-PCR). FGFR3 and PIK3CA mutation analysis was conducted by Competitive Allele-Specific TaqMan ${ }^{\circledR}$ PCR technology (Thermo Fisher Scientific, Inc.), as previously described (32). For FGFR3, mutation detection assays were Hs00000811_mu, Hs00000812_mu and Hs00001342_mu, disclosing FGFR3 variants p.R248C, p.S249C and p.K650Q in the FGFR3 gene, respectively; reference assay Hs00001015_rf was used to recognize wild-type FGFR3. For PIK3CA, mutation detection assays were Hs00000822_mu, Hs00000824_mu and Hs00000831_mu, disclosing variants p.E542K, p.E545K and p.H1047R in the PIK3CA gene, respectively; reference assay Hs00001025_rf was used to recognize wild-type PIK3CA.

Treatment with FGFR and PI3K inhibitors following cell seeding and experimental set up

Cell seeding. In most cases and assays, 5,000 cells were seeded in 80-100 $\mu \mathrm{l}$ medium/well (without penicillin and streptomycin) in 96-well plates, and the edges were filled with medium to avoid edge effects. 
Treatment with FGFR and PI3K inhibitors. The cells were treated with inhibitors $24 \mathrm{~h}$ after seeding. Dactolisib (BEZ235, NVP-BEZ235) and Buparlisib (BKM120, NVP-BKM120) were used as PI3K inhibitors and AZD4547 as an FGFR inhibitor (all were purchased from Selleck Chemicals). To prepare the stocks, the drugs were diluted in DMSO, and the stocks were later diluted further with PBS and then added to the cells to obtain the final drug concentrations. For all cell lines, the concentrations of AZD4547 used were 5-25 $\mu \mathrm{M}$, and those of BEZ235 and BKM120 0.25-5.0 $\mu \mathrm{M}$. Subsequently, the cells were incubated for 24, 48, 72 and, in some cases, $96 \mathrm{~h}$, and different assays were performed to investigate cell viability, cytotoxicity, apoptosis and proliferation. For the experiments using a combination of FGFR (AZD4547) and the PI3K (BEZ235) inhibitors, the concentrations are summarized in Table SI. All experiments were repeated at least 3 times. Representative images for Fig. S3 were taken by using IncuCyte ${ }^{\circledR}$ S3 Live-Cell Analysis System (Essen Bioscience).

WST-1 viability assay. Cells $\left(5 \times 10^{3}\right.$ cells/well) were seeded in 96-well plates. Drug concentrations were tested in duplicates and one plate was used per time point. After 24, 48 and $72 \mathrm{~h}$, $10 \mu \mathrm{l}$ cell proliferation WST-1 reagent (Roche Diagnostics, Mannheim, Germany) were added to each well containing cells and drugs, cells and PBS (positive control), or only medium (two blank wells; background). The plates were incubated for $1 \mathrm{~h}$ in $37^{\circ} \mathrm{C}$ and the absorbance was measured at $450 \mathrm{~nm}$ using the VersaMax microplate reader (Molecular Devices, LLC). During the analysis, the mean average of the duplicates was formed and the mean blank average was subtracted from every value. The average values were normalized to the average control treated with PBS. Furthermore, the $\mathrm{IC}_{50}$ (inhibitory concentration $50 \%$ ) of the drugs on the cell lines was calculated from log concentration-effect curves in GraphPad Prism Software version 8 (GraphPad Software, Inc.) using non-linear regression analysis.

CellTox ${ }^{T M}$ Green Cytotoxicity assay. The CellTox ${ }^{T M}$ Cytotoxicity assay (Promega Corp.) was performed 48 and $72 \mathrm{~h}$ after drug treatment, according to the manufacturer's instructions. Cells $\left(5 \times 10^{3}\right.$ cells/well) were seeded in Corning ${ }^{\circledR}$ 96 Well Black Polystyrene Microplates matrix active group TC-treated with a clear flat bottom and a sterile lid (Merck) in an end-volume of $80 \mu \mathrm{l}$. Duplicates were prepared for each drug concentration. PBS was used as a base level control instead of drugs, and 2 empty wells filled with medium were used as background. Cell lysis solution ( $4 \mu \mathrm{l}$; Promega Corp.) was added as the positive control and incubated for $30 \mathrm{~min}$ at $37^{\circ} \mathrm{C}$. Thereafter, $20 \mu \mathrm{l} \mathrm{CellTox}{ }^{\mathrm{TM}}$ green dye solution $(1: 100$ dye to buffer assay; Promega Corp.) was added to all wells. To avoid light exposure, the plates were covered in foil and then incubated in a shaker for $15 \mathrm{~min}$ at room temperature. A SPARK $^{\mathrm{TM}} 10 \mathrm{M}$ multimode microplate plate reader (Tecan Group, Ltd., Mannedorf, Switzerland) with a 485-nm excitation and 520-nm emission used for the read-out.

Caspase-Glo ${ }^{\circledR}$ 3/7 assay. The Caspase-Glo ${ }^{\circledR}$ 3/7 Assay was performed directly after the CellTox ${ }^{\mathrm{TM}}$ Assay using the same plates (for further information see instructions from the manufacturer, Promega Corp.); $100 \mu 1$ reagent (Promega
Corp.) was added to each well, apart from the positive control of the CellTox ${ }^{\mathrm{TM}}$ Green Cytotoxicity assay. The plates were incubated at room temperature for $1 \mathrm{~h}$ on the shaker wrapped in tin foil. Luminescence was measured using the Centro LB 960 Microplate Luminometer (Berthold Technologies).

Proliferation assay. The proliferation assay was performed using E-plate VIEW 16 plates (ACEA Biosciences, Inc.) in an xCELLigence RTCA DP instrument. To measure the background, $50 \mu \mathrm{l}$ medium were added into each well. Thereafter, $5 \times 10^{3}$ cells in $50 \mu 1$ medium were seeded into the E-plates to a total of $100 \mu \mathrm{l}$. The plates were incubated in the hood for $30 \mathrm{~min}$ at room temperature to allow the cells settle, and were then inserted into the machine. The machine was programmed to take measurements every $2 \mathrm{~h}$. After $24 \mathrm{~h}$, the drugs and PBS (as a control) were added; the measurements were then continued for $90 \mathrm{~h}$. The resulting values were expressed as a cell index, a dimensionless value, which changes in response to cell number or morphological changes.

Western blot analysis. Protein extracts were lysed on ice with Pierce RIPA buffer (Thermo Fisher Scientific, Inc.) containing Halt Protease and Phosphatase Inhibitor Cocktail (100X) (Thermo Fisher Scientific, Inc.). Protein concentrations were determined using detergent compatible (DC)-Protein assay (Bio-Rad) following the manufacturer's protocol. A total of $45 \mu \mathrm{g}$ of protein was diluted (1:3) in Blue Loading Buffer pack containing DTT according to the manufacturer's protocol (New England Biolabs, through BioNordika). Diluted samples were incubated $10 \mathrm{~min}$ at $95^{\circ} \mathrm{C}$, loaded on a MiniProtean TGX (Tris-Glycine eXtended) 10\% gel (Bio-Rad), and finally transferred onto a nitrocellulose membrane (GE Healthcare) overnight at $22 \mathrm{~V}$. The membranes were blocked using non-fat dry milk of $5 \%$ in $0,1 \%$ TBST (Tris-buffered saline, $0.1 \%$ Tween-20) and incubated with primary antibodies overnight at $4^{\circ} \mathrm{C}$ at a dilution of 1:1,000 against PI3K (\#4249S, Cell Signaling Technology, through BioNordika,), 1:2,000 against FGFR3 (ab133644, Abcam) and 1:10,000 against GAPDH (ab8245, Abcam). HRP-conjugated anti-mouse (\#7076, Cell Signaling Technology, 1:5,000) or anti-rabbit (\#7074, Cell Signaling Technology, 1:2,000) diluted in blocking buffer were used as secondary antibodies. Membranes were incubated with ECL (Enhanced chemiluminescence) detection reagent SuperSignal West Pico Plus (Thermo Fisher Scientific) and subsequently the membrane was exposed to a chemiluminescent machine (GE Healthcare). UPCI-SCC-154 and UT-SCC-60A cell lines were used as a positive control, since they had been tested by us previously (unpublished data). In addition, they did not express the most common FGFR3 and PIK3CA mutations, and for further details of the cell lines see Holzhauser et al, 2019 (33).

Statistical analysis. To determine the effects of single or combination treatments, a multiple t-test accompanied by a correction for multiple comparison of the means conferring to the Holm-Sidak method was performed. More specifically, the combined effects were analyzed using the effect-based approach 'Highest Single Agent' and dose-effect-based approach 'median-effect method' (based on Loewe Additivity) (34). The 'Highest Single Agent' method 
determines whether the achieved effect of a drug combination $\left(\mathrm{E}_{\mathrm{AB}}\right)$ is larger than the effect obtained by any of the individual drugs $\left(\mathrm{E}_{\mathrm{A}}\right.$ and $\left.\mathrm{E}_{\mathrm{B}}\right)$. A combination index $(\mathrm{CI})$ was calculated using the formula $\mathrm{CI}=\max \left(\mathrm{E}_{\mathrm{A}}, \mathrm{E}_{\mathrm{B}}\right) / \mathrm{E}_{\mathrm{AB}}$. A CI of $<1$ was considered a positive and a $\mathrm{CI}$ of $>1$ a negative combined effect. In addition, the combined effects were analyzed using the median-effect method of Chou (Chou-Talalay method) (35) using ComboSyn software (http://www. combosyn.com; ComboSyn, Inc.). The dose-response curves were fitted to a linear model using the median-effect equation, allowing for the calculation of a median-effect value D (equivalent to IC50) and slope. Goodness-of-fit was assessed with the linear correlation coefficient, $r$; An $r>0.85$ was required for the analysis to be approved. The degree of drug interaction was rated using the CI for mutually exclusive drugs: $C I=d_{1} / D_{1}+d_{2} / D_{2}$, where $D_{1}$ and $D_{2}$ represent the concentration of drug 1 and 2 alone, respectively, that is required to produce a certain effect, and $d_{1}$ and $d_{2}$ represent the concentration of drugs 1 and 2 in combination that is required to produce the same effect. Herein, $\mathrm{CI}<0.70$ was defined as synergy and $\mathrm{CI}<1.45$ as antagonism, and values in between as additive effects, according to the recommendations of the ComboSyn software. One-way ANOVA with the Bonferroni post-hoc test was used to analyze the difference in means between the two single drugs and the combined treatment. A $\mathrm{P}<0.05$ was considered to indicate a statistically significant difference.

\section{Results}

Analysis of FGFR3 and PIK3CA mutations in NB by CAST-PCR. A total of $29 \mathrm{NB}$ samples were evaluated for FGFR 3 and PIK3CA mutations by CASR-PCR, and only one of these tumors was found to have an FGFR3 mutation. This mutation was FGFR3 K650Q (data not shown).

Analysis of FGFR3 $m R N A$ expression with regard to $N B$ survival and genetic dependency, and FGFR3 protein expression in NB cell lines. Since PI3K inhibitors have shown promising results in NB $(17,18)$, the importance of $F G F R 3$ and genetic inhibition of FGFR3 in NB was investigated in publicly available data. First, the mRNA expression levels were analyzed in a publicly available validated cohort of NB samples, and it was found that a higher FGFR3 mRNA expression was significantly associated with a worse event-free, as well as overall, survival (Fig. S1A). Secondly, the analysis of publicly available RNAi screening data revealed a significant FGFR3 dependency in the investigated NB cell lines, as compared to cell lines from other cancer diagnoses (Fig. S1B). When investigated by Western blot analysis, evident levels of FGFR3 and PI3K protein expression in NB cell lines were demonstrated (Fig. S2).

Treatment of $S K-N-A S, S K-N-B E(2)-C, S K-N-D Z, S K-N-F I$ and $S K-N-S H N B$ cell lines with FGFR and PI3K inhibitors independently

$W S T-1$ viability analysis following treatment of $S K-N-A S$, $S K-N-B E(2)-C, S K-N-D Z, S K-N-F I$ and $S K-N-S H N B$ cell lines with FGFR and PI3K inhibitors independently. To examine the effects of the treatment on cell viability, WST-1 viability assays were performed at 24,48 and $72 \mathrm{~h}$ following treatment of the SK-N-AS, SK-N-BE(2)-C, SK-N-DZ, SK-N-FI and SK-N-SH cell lines with various concentrations of the FGFR inhibitor, AZD4547, and the PI3K inhibitors, BEZ235 and BKM120. All absorbance values were compared to those of the PBS control.

AZD4547. The FGFR3 inhibitor, AZD4547, induced a dose-dependent effect on cell viability in all 5 investigated cell lines. All $5 \mathrm{NB}$ cell lines exhibited a $\geq 50 \%$ decrease in absorbance (i.e., a decrease in the number of metabolically active cells) following treatment with $25 \mu \mathrm{M}$ AZD4547 at 24, 48 and 72 h (at least $\mathrm{P}<0.01$; Fig. 1A-E). The SK-N-BE(2)-C, SK-N-DZ and SK-N-SH also exhibited a $\geq 50 \%$ decrease in absorbance following treatment with $10 \mu \mathrm{M}$ AZD4547 for $72 \mathrm{~h}$, which was also the case for the SK-N-BE(2)-C and SK-N-SH cells already at $48 \mathrm{~h}$ (at least $\mathrm{P}<0.05$ ), but not at all the case for the SK-N-AS and SK-N-FI cells (Fig. 1A-E). Treatment with $5 \mu \mathrm{M}$ AZD4547 was less effective for all cell lines (Fig. 1A-E).

BEZ235. The PI3K inhibitor, BEZ235, exerted a dose-dependent effect on cell viability in the majority of the investigated cell lines, and most evidently in the 2 $M Y C N$-amplified cell lines, SK-N-BE(2)-C and SK-N-DZ, but also in the SK-N-SH, SK-N-AS and SK-N-FI cells. More specifically, as compared to the PBS control, $a \geq 50 \%$ decrease in absorbance was observed in all $5 \mathrm{NB}$ cell lines following treatment with $5 \mu \mathrm{M}$ BEZ235 after 48 and $72 \mathrm{~h}$ (at least $\mathrm{P}<0.01$ ), with the $\mathrm{SK}-\mathrm{N}-\mathrm{DZ}$ and $\mathrm{SK}-\mathrm{N}-\mathrm{SH}$ also exhibiting the decrease after $24 \mathrm{~h}$ (at least $\mathrm{P}<0.01$; Fig. 1F-J). SK-N-DZ and SK-N-SH were the cell lines most sensitive to BEZ235, exhibiting a $\geq 50 \%$ decrease in absorbance with $0.25-1 \mu \mathrm{M}$ BEZ235 at 48 and $72 \mathrm{~h}$ (at least $\mathrm{P}<0.05)$, and SK-N-DZ with $1 \mu \mathrm{M}$ BEZ235 at $24 \mathrm{~h}(\mathrm{P}<0.01$; Fig. $1 \mathrm{H}$ and $\mathrm{J})$. Finally, at $0.25-1 \mu \mathrm{M}$ BEZ235, $\mathrm{a} \geq 50 \%$ decrease in absorbance was also observed at $72 \mathrm{~h}$ in the SK-N-AS and SK-N-BE(2)-C (at least $\mathrm{P}<0.01$ for all), but not in the SK-N-FI (Fig. 1F, G and I, respectively) cells.

BKM120. The PI3K inhibitor, BKM120, also exerted a dose-dependent effect in the majority of cell lines with a similar, but slightly less sensitive, pattern than that of BEZ235. Treatment with $5 \mu \mathrm{M}$ BKM120 induced a $\geq 50 \%$ decrease in absorbance after 48 and $72 \mathrm{~h}$ in all NB lines (at least $\mathrm{P}<0.05$ for all). This decrease in absorbance was also observed in the SK-N-AS, SK-N-DZ and SK-N-SH cells after $24 \mathrm{~h}$, as compared to the PBS control (at least $\mathrm{P}<0.05$ for all; Fig. 1K-O). Following treatment with $1 \mu \mathrm{M}$ BKM120, a $\geq 50 \%$ decrease in absorbance was observed in the SK-N-BE(2)-C and SK-N-SH cells after $72 \mathrm{~h}$ (Fig $1 \mathrm{~L}$ and $\mathrm{O}$; at least $\mathrm{P}<0.001$ ). The lower BKM120 concentrations did not exert any notable effects (Fig. 1K-O).

IC50. To better evaluate the sensitivity of the different cell lines, IC50 values for all cell lines were calculated and are presented in Table I. The data indicated that the SK-N-SH cells were the most sensitive and the SK-N-FI cells the most insensitive to treatment with AZD4547, with SK-N-AS being somewhat less insensitive, and the SK-N-BE(2)-C and SK-N-DZ cells 

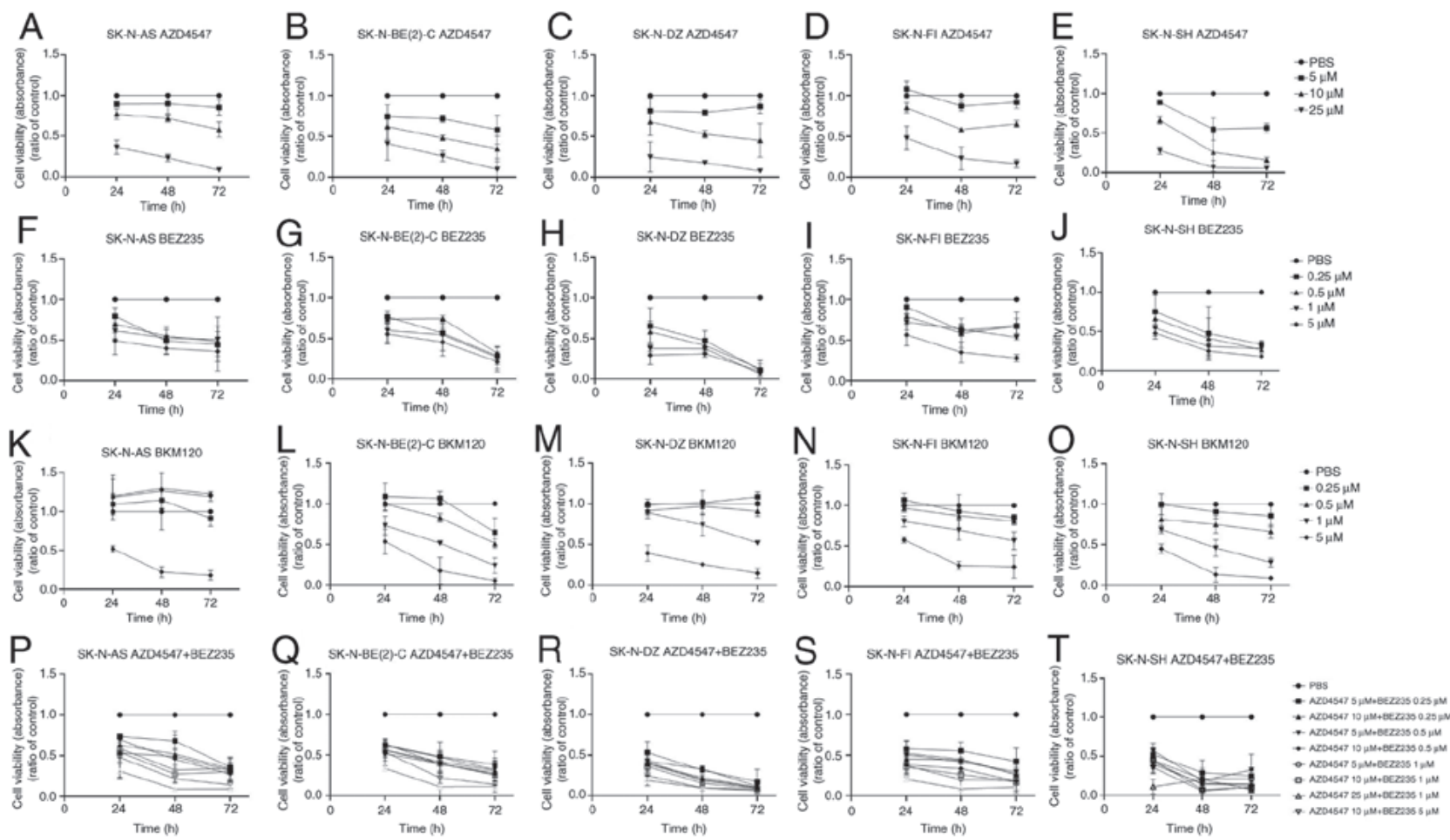

Figure 1. WST-1 viability assays on the SK-N-AS, SK-N-BE(2)-C, SK-N-DZ, SK-N-FI and SK-N-SH cell lines. WST-1 viability assay measured the absorbance following treatment for 24, 48 and $72 \mathrm{~h}$ of the SK-N-AS, SK-N-BE(2)-C, SK-N-DZ, SK-N-FI and SK-N-SH cells with (A-E) the FGFR inhibitor, AZD4547, and the PI3K inhibitors (F-J) BEZ235 and (K-O) BKM120, respectively. (P-T) Combined treatment of the SK-N-AS, SK-N-BE(2)-C, SK-N-DZ, SK-N-FI and SK-N-SH cells with the FGFR inhibitor, AZD4547, and PI3K inhibitor, BEZ235. The graphs represent 3 experimental runs per cell line and results are presented as the means \pm SD. FGFR, fibroblast growth factor receptor; PI3K, phosphoinositide 3-kinase.

somewhere in between. For BEZ235 and BKM120, the IC50 values indicated that the SK-N-DZ and SK-N-SH cells and, to a certain extent, the SK-N-BE(2)-C cells, were the cell lines most sensitive to both these drugs, followed by the other cell lines (Table I).

CellTox ${ }^{T M}$ Green Cytotoxicity assay following treatment of the $S K-N-A S, S K-N-B E(2)-C, S K-N-D Z, S K-N-F I$ and $S K-N-S H$ $N B$ cell lines with the FGFR inhibitor, AZD4547, and PI3K inhibitor, BEZ235, independently.

General set up. The CellTox ${ }^{\mathrm{TM}}$ Green Cytotoxicity assays were performed on the SK-N-AS, SK-N-BE(2)-C, SK-N-DZ, SK-N-FI and SK-N-SH NB cell lines at 48, 72 and $96 \mathrm{~h}$ following treatment with the FGFR and PI3K inhibitors. The cytotoxic effect of the positive control was significantly higher than all other effects in all cases. Only increases in fluorescence, as compared to the PBS control, were observed and are described below.

AZD4547. Following treatment with $25 \mu \mathrm{M}$ AZD4547 for $48 \mathrm{~h}$, a significant increase in fluorescence was observed in all cell lines (at least $\mathrm{P}<0.05$ ) apart from the $\mathrm{SK}-\mathrm{N}-\mathrm{BE}(2)-\mathrm{C}$ cells. After $72 \mathrm{~h}$, this effect was observed in all cell lines (at least $\mathrm{P}<0.05$; Fig. $2 \mathrm{~A}-\mathrm{E})$. After $48 \mathrm{~h}$ of treatment with $10 \mu \mathrm{M}$ AZD4547, a significant increase in fluorescence was observed in the SK-N-AS, SK-N-FI and SK-N-SH cell lines (at least $\mathrm{P}<0.01$ ) (Fig. 2A-E).

BEZ235. Only sporadically were minor significant increases observed in the majority of cell lines (Fig. 2F, G, I and J).
Caspase-Glo 3/7 apoptosis assay following treatment of the $S K-N-A S, S K-N-B E(2)-C, S K-N-D Z, S K-N-F I$ and $S K-N-S H$ $N B$ cell lines with the FGFR inhibitor, AZD4547, and PI3K inhibitor, BEZ235 independently

General set up. The effect on apoptosis was evaluated by Caspase-Glo 3/7 apoptosis assay 48, 72 and $96 \mathrm{~h}$ following treatment of the SK-N-AS, SK-N-BE(2)-C, SK-N-DZ, SK-N-FI and SK-N-SH cell lines with the FGFR inhibitor, AZD4547, and the PI3K inhibitor, BEZ235, at various concentrations normalized against PBS. Only increases in luminescence, as compared to the PBS control, were observed and are described below.

AZD4547. A significant increase in apoptosis (i.e., in luminescence) was observed at $48 \mathrm{~h}$ in the SK-N-FI and SK-N-BE(2)-C cells lines (at least $\mathrm{P}<0.01$ ) and at $72 \mathrm{~h}$ in the $\mathrm{SK}-\mathrm{N}-\mathrm{BE}(2)-\mathrm{C}$, SK-N-FI and SK-N-SH cells lines (at least $\mathrm{P}<0.05$ ) following treatment with $25 \mu \mathrm{M}$ AZD4547, as compared to the PBS control, but not in the SK-N-AS and SK-N-DZ cells lines, as shown in Fig. 3A-E. A significant increase in luminescence was also observed in the SK-N-SH cells at 48 and $72 \mathrm{~h}$ following treatment with $10 \mu \mathrm{M}$ AZD4547 (at least $\mathrm{P}<0.05$; Fig. 3E). No significant increases were observed in the cell lines at a concentration of $5 \mu \mathrm{M}$ AZD4547.

BEZ235. No significant increases in apoptosis (i.e., luminescence) were observed in any of the cell lines, as compared to the PBS control (Fig. 3F-J), although there was a tendency towards an increase in luminescence in the SK-N-FI cell line following $48 \mathrm{~h}$ of treatment with $5.0 \mu \mathrm{M}$ BEZ235 (Fig. 3I). 
Table I. WST-1 viability analysis following treatment with the FGFR inhibitor, AZD4547, and PI3K inhibitors, BEZ235 and BKM120 for 24, 48 and $72 \mathrm{~h}$.

\begin{tabular}{|c|c|c|c|c|c|}
\hline \multirow{3}{*}{$\begin{array}{l}\text { Cell line } \\
\text { SK-N-AS }\end{array}$} & & & \multicolumn{3}{|c|}{$\mathrm{IC}_{50}(\mu \mathrm{M})$} \\
\hline & \multicolumn{2}{|c|}{ Drugs } & \multirow{2}{*}{$\frac{24 \mathrm{~h}}{18.4}$} & \multirow{2}{*}{$\frac{48 \mathrm{~h}}{14.7}$} & \multirow{2}{*}{$\frac{72 \mathrm{~h}}{11.0}$} \\
\hline & FGFR & AZD4547 & & & \\
\hline & PI3K & BEZ235 & 3.02 & 0.743 & 0.318 \\
\hline & & BKM120 & $8.53^{\mathrm{a}}$ & $5.08^{\mathrm{a}}$ & 2.82 \\
\hline \multirow[t]{3}{*}{ SK-N-BE(2)-C } & FGFR & AZD4547 & 16.8 & 10.0 & 6.33 \\
\hline & PI3K & BEZ235 & $>5.00^{\mathrm{b}}$ & 2.22 & $<0.250^{b}$ \\
\hline & & BKM120 & $5.20^{\mathrm{a}}$ & 1.20 & 0.448 \\
\hline \multirow[t]{3}{*}{ SK-N-DZ } & FGFR & AZD4547 & 13.9 & 10.6 & 9.43 \\
\hline & PI3K & BEZ235 & 0.711 & 0.123 & $<0.250^{b}$ \\
\hline & & BKM120 & 3.75 & 2.36 & 1.04 \\
\hline \multirow[t]{3}{*}{ SK-N-FI } & FGFR & AZD4547 & 23.9 & 12.6 & 12.9 \\
\hline & PI3K & BEZ235 & 7.39 & 1.54 & 1.20 \\
\hline & & BKM120 & 6.37 & 2.11 & 1.55 \\
\hline \multirow[t]{3}{*}{ SK-N-SH } & FGFR & AZD4547 & $1.15^{\mathrm{a}}$ & $0.741^{\mathrm{a}}$ & $0.735^{\mathrm{a}}$ \\
\hline & PI3K & BEZ235 & 2.99 & $0.168^{\mathrm{a}}$ & $<0.250^{b}$ \\
\hline & & BKM120 & 3.57 & 0.996 & 0.665 \\
\hline
\end{tabular}

The $\mathrm{IC}_{50}$ (inhibitory concentration 50\%) for each cell line for each drug was determined from log concentrations-effect curves in GraphPad Prism using non-linear regression analysis. FGFR3, fibroblast growth factor receptor 3. ${ }^{a}$ Extrapolated IC50 value, i.e., outside the tested concentration range. ${ }^{b}$ The IC50 value could not be determined; lowest/highest tested concentration closest to the IC50 is reported.
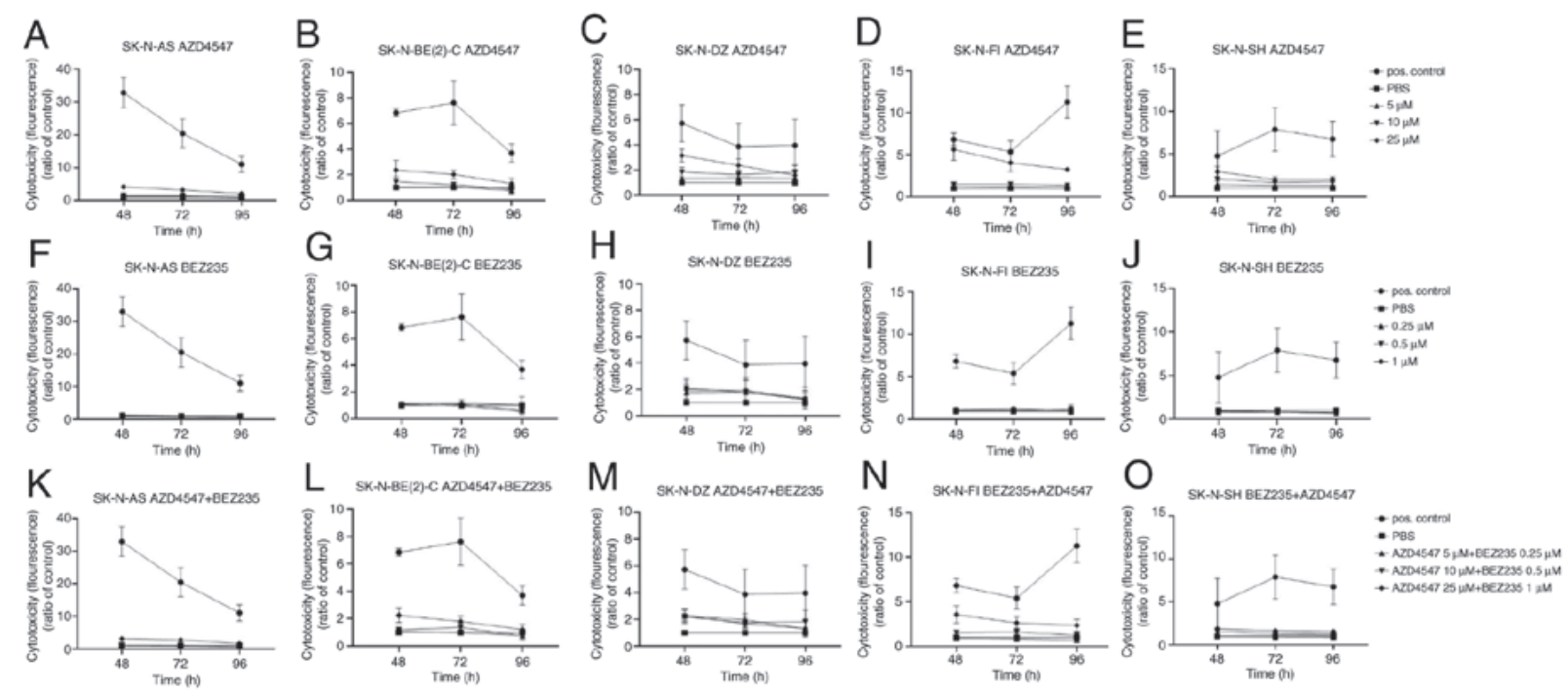

Figure 2. CellTox ${ }^{\mathrm{TM}}$ Green Cytotoxicity assay on the SK-N-AS, SK-N-BE(2)-C, SK-N-DZ, SK-N-FI and SK-N-SH cell lines. CellTox ${ }^{\mathrm{TM}}$ Green cytotoxicity assay was performed by measuring fluorescence following treatment of the aforementioned NB cell lines with (A-E) the FGFR inhibitor, AZD4547, and (F-J) PI3K inhibitor, BEZ235 for 48, 72 and 96 h. (K-O) Combined treatment of the aforementioned cell lines with the FGFR inhibitor, AZD4547, and PI3K inhibitor, BEZ235. The graphs represent 3 experimental runs per cell line and results are presented as the means \pm SD. NB, neuroblastoma; FGFR, fibroblast growth factor receptor; PI3K, phosphoinositide 3-kinase.

Proliferation assay using the $x$ CELLigence System following treatment of the $S K-N-A S, S K-N-B E(2)-C$, $S K-N-D Z, S K-N-F I$ and $S K-N-S H N B$ cell lines with the FGFR inhibitor, AZD4547, and PI3K inhibitor, BEZ235, independently

General set up. The xCELLigence System was used to follow proliferation for $90 \mathrm{~h}$ following treatment of the SK-N-AS,
SK-N-BE(2)-C, SK-N-DZ, SK-N-FI and SK-N-SH NB cell lines with the FGFR AZD4547 and PI3K BEZ235 inhibitors. PBS was used as a control.

AZD4547. Complete or considerate inhibition was observed in all cell lines with $25 \mu \mathrm{M}$, but not with $5 \mu \mathrm{M}$ AZD4547 during the entire observation period (Fig. 4A-E). 

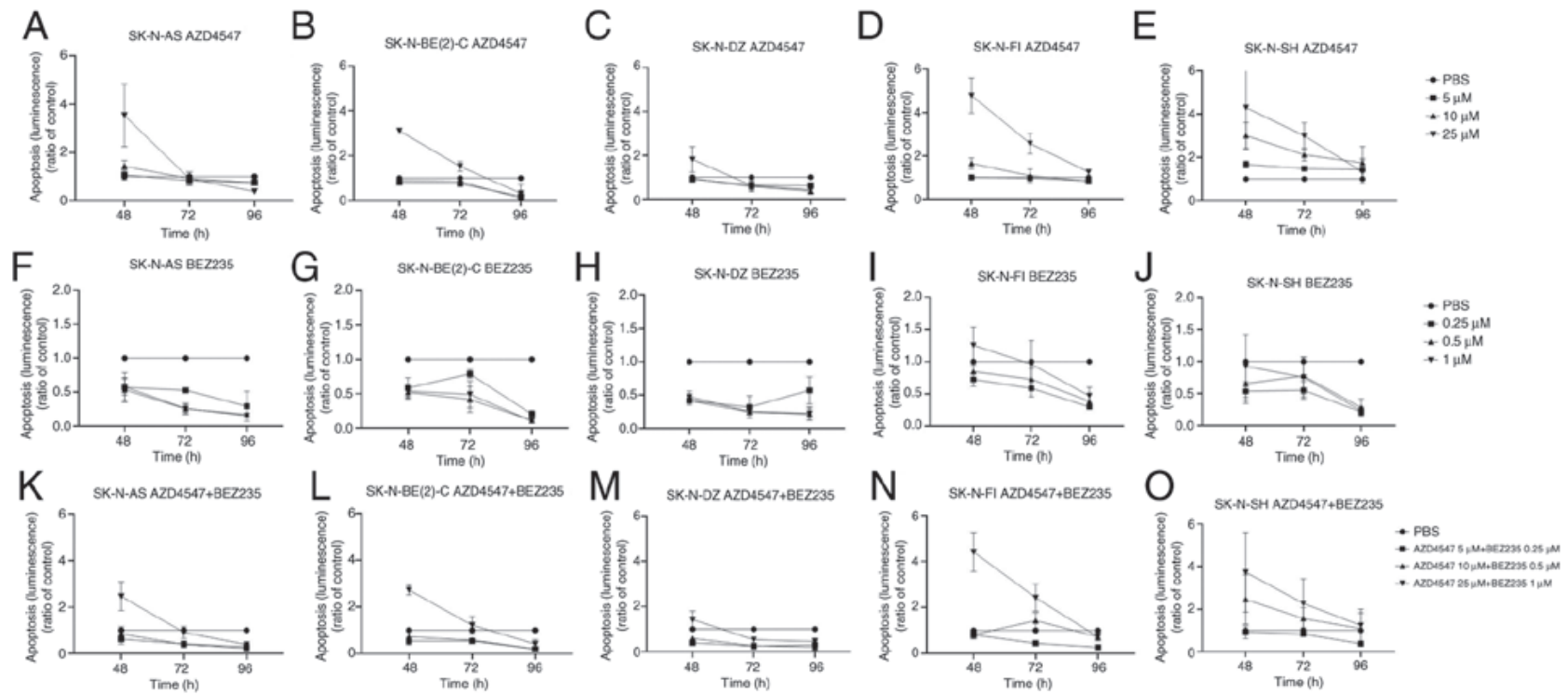

Figure 3. Caspase-Glo 3/7 apoptosis assay of the SK-N-AS, SK-N-BE(2)-C, SK-N-DZ, SK-N-FI and SK-N-SH cell lines. Caspase-Glo 3/7 apoptosis assay measured by luminescence following treatment of the 5 neuroblastoma cell lines with (A-E) the FGFR inhibitor, AZD4547, and (F-J) PI3K inhibitor, BEZ235, for 48, 72 and 96 h. (K-O) Combined treatment of the cells lines with the FGFR inhibitor, AZD4547, and PI3K inhibitor, BEZ235. The graphs represent 3 experimental runs per cell line and results are presented as the means \pm SD. FGFR, fibroblast growth factorreceptor; PI3K, phosphoinositide 3-kinase.
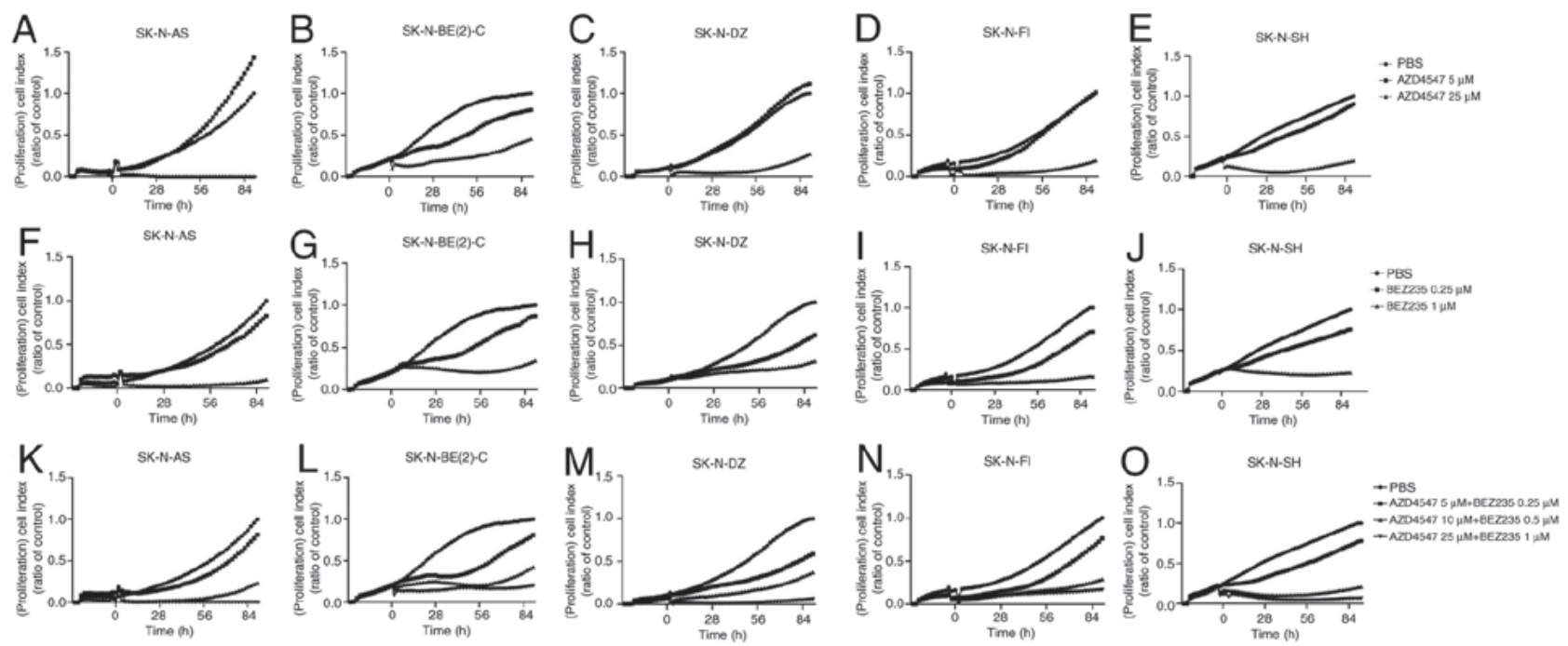

Figure 4. Proliferation assay performed on SK-N-AS, SK-N-BE(2)-C, SK-N-DZ, SK-N-FI and SK-N-SH cell lines. Proliferation assay results were expressed as cell index following treatment with (A-E) the FGFR inhibitor, AZD4547, and (F-J) PI3K inhibitor, BEZ235, on SK-N-AS, SK-N-BE(2)-C, SK-N-DZ, SK-N-FI and SK-N-SH cell lines, respectively. (K-O) Combined treatment with the FGFR inhibitor, AZD4547, and PI3K inhibitor, BEZ235, on these cell lines. The graphs represent one typical experiment, and results are presented as the mean of two wells. FGFR, fibroblast growth factor receptor; PI3K, phosphoinositide 3-kinase.

BEZ235. Complete or considerable inhibition of proliferation was observed in all NB lines during the observation period following treatment with 1 but not $0.25 \mu \mathrm{MBEZ235}$ (Fig. 4F-J).

Treatment of the $S K-N-A S, S K-N-B E(2)-C, S K-N-D Z$, $S K-N-F I$ and $S K-N-S H N B$ cell lines with the FGFR inhibitor, AZD4547, and the PI3K inhibitor, BEZ235, in combination.

General set up. The inhibitory effects on cell viability and proliferation following treatment with the FGFR inhibitor, AZD4547, and the PI3K inhibitors, BEZ235 and BKM120, are shown above. To further examine the potential therapeutic role of these drugs and explore whether lower drug concentrations could be used, two types of drugs were combined and examined. For this purpose, cell viability, cytotoxicity, apoptosis and proliferation were analyzed in all 5 NB cell lines using the WST-1, CellTox ${ }^{\mathrm{TM}}$ Green Cytotoxicity and Caspase-Glo 3/7 apoptosis assays, and the xCELLigence System, respectively. The SK-N-SH, and possibly the SK-N-DZ cells, were found above to be generally more sensitive cell lines, while the SK-N-AS, SK-N-BE(2)-C and SK-N-FI more resistant/intermediately sensitive cell lines.

$W S T-1$ viability analysis following treatment of $S K-N-A S$, $S K-N-B E(2)-C, S K-N-D Z, S K-N-F I$ and $S K-N-S H N B$ cell lines with FGFR inhibitor AZD4547 and PI3K inhibitor BEZ235 combined. The highest concentration combinations, $25 \mu \mathrm{M}$ AZD4547 and $1 \mu \mathrm{M}$ BEZ235, $10 \mu \mathrm{M}$ AZD4547 and 

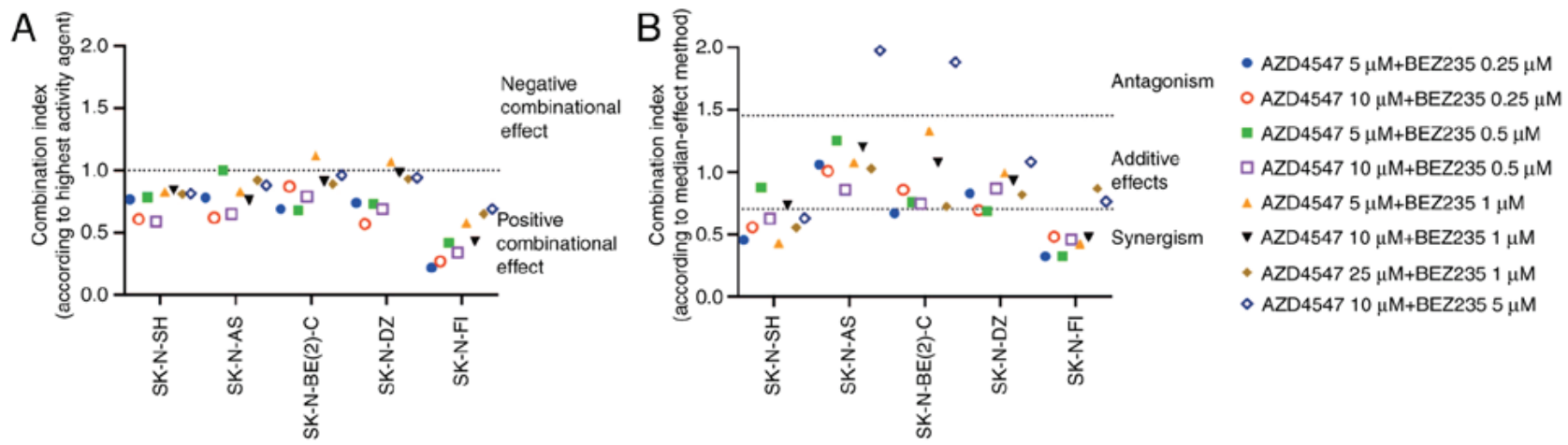

Figure 5. CI from analysis of the combinational effects of treatments with AZD4547 and BEZ235 for $24 \mathrm{~h}$ in NB cell lines. CIs were obtained by (A) the highest single agent approach, where $\mathrm{CI}<1$ indicates a positive and $\mathrm{CI}>1$ a negative combination effect, and (B) the median-effect method, where $\mathrm{CI}<0.7$ suggests synergy, CI $>1.45$ antagonism and $0.7<\mathrm{CI}>1.45$ additive combinational effects. CIs were calculated from the mean of three experiments, analyzed by WST-1. $\mathrm{CI}$, combination index; NB, neuroblastoma.

$5 \mu \mathrm{M}$ BEZ235, as well as $10 \mu \mathrm{M}$ AZD4547 and $1 \mu \mathrm{M}$ BEZ235, induced a $\geq 50 \%$ decrease in absorbance in all NB cell lines during the entire observation period (at least $\mathrm{P}<0.05$; Fig. 1P-T).

Lower concentration combinations of $10 \mu \mathrm{M}$ AZD4547 and $0.5 \mu \mathrm{M}$ BEZ235, $10 \mu \mathrm{M}$ AZD4547 and $0.25 \mu \mathrm{M}$ BEZ235, $5 \mu \mathrm{M}$ AZD4547 and $1 \mu \mathrm{M}$ of BEZ235, as well as $5 \mu \mathrm{M}$ AZD4547 and $0.5 \mu \mathrm{M}$ BEZ235, also induced $\mathrm{a} \geq 50 \%$ decrease in absorbance at $48-72 \mathrm{~h}$ in all NB lines (at least $\mathrm{P}<0.05$ ) (Fig. 1P-T).

The lowest concentration combination, $5 \mu \mathrm{M}$ AZD4547 and $0.25 \mu \mathrm{M}$ BEZ235, resulted in a $\geq 50 \%$ decrease in absorbance after $72 \mathrm{~h}$ for all cell lines, which was also observed after 24 and $48 \mathrm{~h}$ in SK-N-BE(2)-C, SK-N-DZ and SK-N-SH cell lines (at least $\mathrm{P}<0.01$; Fig. 1P-T).

Combined effect analysis was also performed to further evaluate possible positive synergism, the additive effects or antagonism between the two drugs that were used. Two different approaches were used: The effect-based highest single agent approach and dose-effect-based median-effect principle. CIs from both methods assessing the combinational effect in SK-N-AS, SK-N-BE(2)-C, SK-N-DZ, SK-N-FI and SK-N-SH cell lines at $24 \mathrm{~h}$ are displayed in Fig. 5. All tested combinations, apart from two, were rated as positive by the highest single agent approach (Fig. 5A) and additive/synergistic by the median-effect principle (Fig. 5B). Viability following treatment of the cell lines with single doses of AZD4547 and BEZ235, as well as dose combinations, was also illustrated in staple diagrams. These diagrams are illustrated in Fig. 6, following $24 \mathrm{~h}$ of treatment of the sensitive SK-N-SH and more resistant SK-N-FI cell lines with different drug combinations. At $24 \mathrm{~h}$, the decrease in viability was significant in the SK-N-SH cell line in $3 / 8$ tested combinations (Fig. 6B, D and G), and in the more resistant SK-N-FI in 6/8 combinations (Fig. 6I-L, $\mathrm{N}$ and $\mathrm{O}$ ), as compared to both single drugs. Particularly in the SK-N-FI cell line, a potent synergistic effect on cell viability was observed at the lower dose combinations (5 or $10 \mu \mathrm{M}$ AZD4547 and $0.25 \mu \mathrm{M}$ or $0.5 \mu \mathrm{M}$ BEZ235), whereas the single drugs had a minor or no effect (Fig. 6I-L). No combination in any of the 5 tested cell lines induced a significantly weaker effect on viability than AZD4547 and BEZ235 alone (data not shown).
CellTox ${ }^{T M}$ Green Cytotoxicity assay following combined treatment of the $S K-N-A S, S K-N-B E(2)-C, S K-N-D Z$, $S K-N-F I$ and $S K-N$-SH NB cell lines with the FGFR inhibitor, AZD4547, and the PI3K inhibitor, BEZ235. CellTox ${ }^{\mathrm{TM}}$ Green Cytotoxicity assay was performed with FGFR and PI3K inhibitors used in combination on the SK-N-AS, SK-N-BE(2)-C, SK-N-DZ, SK-N-FI and SK-N-SH NB cell lines at 48, 72 and $96 \mathrm{~h}$ after treatment. The cytotoxic effect of the positive control was significantly higher than all other effects in all cases. Differences in fluorescence were calculated in comparison to the PBS base line control.

The highest concentration combination, $25 \mu \mathrm{M}$ AZD4547 and $1 \mu \mathrm{M}$ BEZ235, induced a significant increase in fluorescence, as compared to PBS at $48 \mathrm{~h}$ following treatment in all cell lines (at least $\mathrm{P}<0.05$ ); after $72 \mathrm{~h}$ for the SK-N-AS, SK-N-DZ, SK-N-FI and SK-N-SH cells (at least $\mathrm{P}<0.05$ ), and after $96 \mathrm{~h}$ for the SK-N-AS, SK-N-FI and SK-N-SH (at least $\mathrm{P}<0.05$ ) (Fig. 2K-O).

The intermediate concentration combination, $10 \mu \mathrm{M}$ AZD4547 and $0.5 \mu \mathrm{M}$ BEZ235, induced a significant increase in fluorescence at $48 \mathrm{~h}$ following treatment only of the SK-N-BE(2)-C and SK-N-FI cells (at least P<0.05; Fig. 2K-O).

The lowest concentration combination, $5 \mu \mathrm{M}$ AZD4547 and $0.25 \mu \mathrm{M}$ of BEZ235, induced a significant increase in fluorescence after $48 \mathrm{~h}$ only in the SK-N-BE(2)-C and SK-N-DZ (at least $\mathrm{P}<0.05$; Fig. 2K-O).

Caspase-Glo 3/7 apoptosis assay following combined treatment of the $S K-N-A S, S K-N-B E(2)-C, S K-N-D Z, S K-N-F I$ and $S K-N-S H N B$ cell lines with the FGFR inhibitor, AZD4547, and PI3K inhibitor, BEZ235. To evaluate the effects of treatment on apoptosis, Caspase-Glo 3/7 apoptosis assay was performed 48,72 and $96 \mathrm{~h}$ following treatment of the SK-N-AS, SK-N-BE(2)-C, SK-N-DZ, SK-N-FI and SK-N-SH cell lines with a combination of various concentrations of the FGFR inhibitor, AZD4547, and PI3K inhibitor, BEZ235. Only increases in luminescence, as compared to the PBS control, were observed and are described below.

The highest concentration combination, $25 \mu \mathrm{M}$ AZD4547 and $1 \mu \mathrm{M}$ BEZ235, induced a significant increase in apoptosis (i.e., luminescence) in all cell lines apart from the 

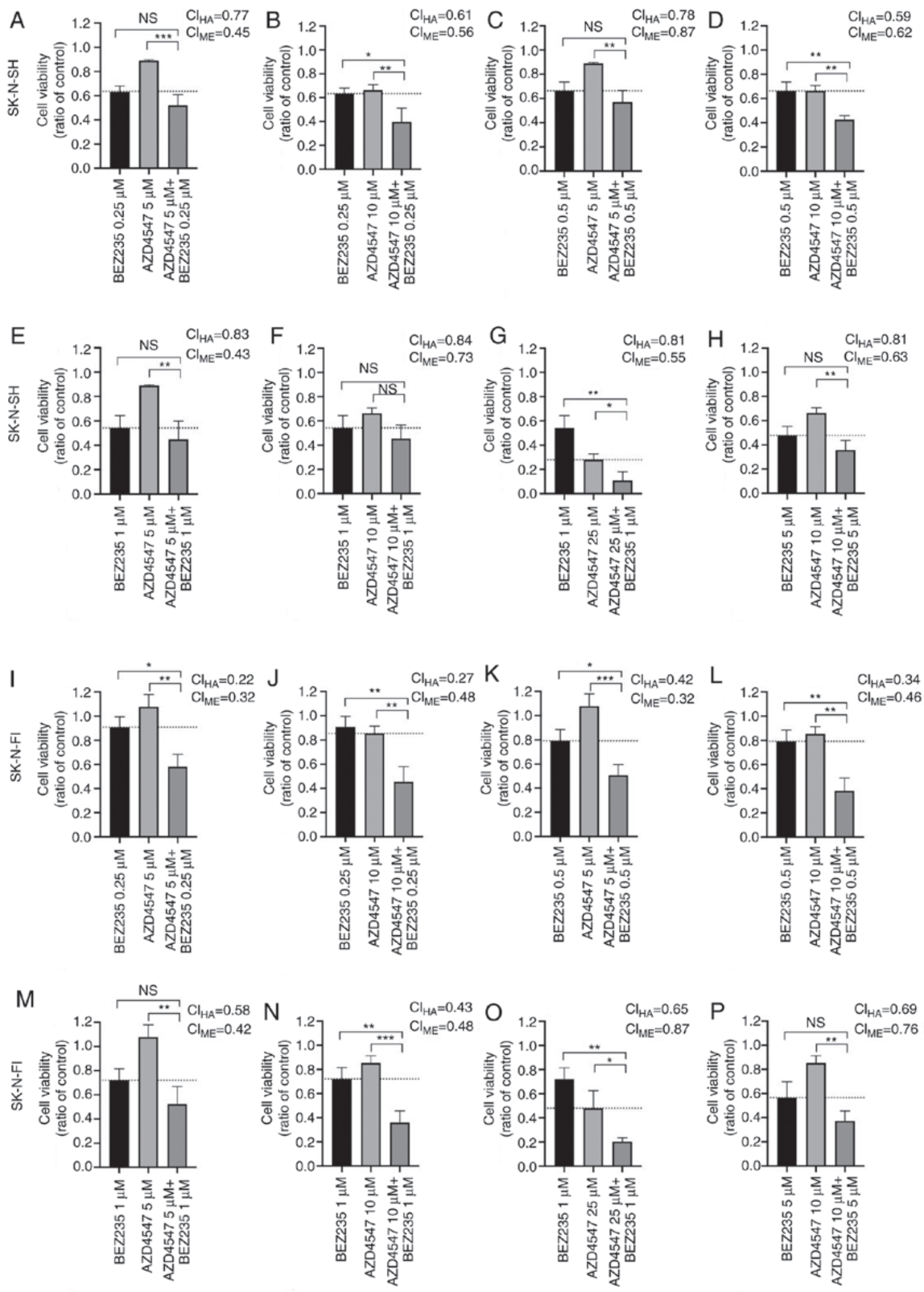

Figure 6. Combinational effects of AZD4547 and BEZ235 in (A-H) SK-N-SH and (I-P) SK-N-FI, NB cell lines. Effect on cell viability following 24 h of single and combination treatments with AZD4547 and BEZ235, as determined by WST-1 analysis. The CIs displayed in the graphs were calculated by the highest single agent approach $\left(\mathrm{CI}_{\mathrm{HA}}\right)$, where $\mathrm{CI}<1$ indicated a positive and $\mathrm{CI}>1$ a negative combination effect, and by the median-effect method $\left(\mathrm{CI}_{\mathrm{ME}}\right)$, where $\mathrm{CI}<0.7$ indicated synergy, $\mathrm{CI}>1.45$ antagonism and $0.7<\mathrm{CI}>1.45$ an additive combinational effect. The dotted line represents the effect of the best single drug. Significance between the effect of the combination and that from two single drugs was tested by one-way ANOVA with Bonferroni post-hoc test. ${ }^{*} \mathrm{P}<0.05$, ${ }^{* * *} \mathrm{P}<0.01$ and ${ }^{* * *} \mathrm{P}<0.001$. The graphs represent 3 independent experiments, and results are presented as the means \pm SD. CI, combination index.

SK-N-DZ cells, as compared to PBS $48 \mathrm{~h}$ after treatment (at least $\mathrm{P}<0.05$; Fig. 3K-O).
Following the intermediate concentration combination, $10 \mu \mathrm{M}$ AZD4547 and $0.5 \mu \mathrm{M}$ BEZ235, only a tendency of 
an increase in luminescence was observed at 48 and $72 \mathrm{~h}$ in the SK-N-SH cell line, which was not significant. No significant increases were observed in the other cell lines either (Fig. 3K-O).

The lowest concentration combination, $5 \mu \mathrm{M}$ AZD4547 and $0.25 \mu \mathrm{M}$ BEZ235, did not induce any significant increases in luminescence in any of the cell lines (Fig. 3K-O).

Proliferation assay following treatment with the FGFR inhibitor, AZD4547, and PI3K inhibitor, BEZ235, used in combination on the $S K-N-A S, S K-N-B E(2)-C, S K-N-D Z$, $S K-N-F I$ and $S K-N-S H$ cell lines. The highest concentration combination, $25 \mu \mathrm{M}$ AZD4547 and $1 \mu \mathrm{M}$ BEZ235, induced an almost complete inhibition of proliferation in all cell lines during the entire observation period (Fig. 4K-O).

The intermediate concentration combination, $10 \mu \mathrm{M}$ AZD4547 and $0.5 \mu \mathrm{M}$ BEZ235, produced a considerate, or almost complete, inhibition of the proliferation of all cell lines (Fig. 4K-O).

The lowest concentration combination, $5 \mu \mathrm{M}$ AZD4547 and $0.25 \mu \mathrm{M}$ BEZ235, was not as efficient for any of the tested cell lines, inducing an intermediate (SK-N-DZ) or slight (SK-N-AS, SK-N-BE(2)-C, SK-N-FI and SK-N-SH) inhibition of proliferation (Fig. 4K-O). Representative images of the NB cell lines treated with PI3K and FGFR3 inhibitors alone and in combination are shown in Fig. S3.

\section{Discussion}

NB is a highly lethal disease and novel therapies based on biological understanding are warranted. Herein, the presence of common FGFR3 and PIK3CA mutations were tested in 29 NB tumors. In addition, the ability of FGFR and PI3K inhibitors, alone or in combination, to inhibit the growth of SK-N-AS, SK-N-BE(2)-C, SK-N-DZ, SK-N-FI and SK-N-SH NB cell lines was tested. An FGFR3 mutation was found in $1 / 29 \mathrm{NBs}$, and all $5 \mathrm{NB}$ cell lines were found to be rather sensitive to both the FGFR and PI3K inhibitors alone; the combination of the two drugs considerably increased the inhibitory effect on viability and proliferation.

One of the 29 NBs exhibited an FGFR3 K650Q mutation, which is common, but not the most frequently occurring mutation (36). This is noteworthy, since mutations in childhood cancers are unusual, and there are very few or no reports currently available on FGFR3 mutations in childhood cancer, at least to the best of our knowledge. Nevertheless, it has been reported that FGFR3 mutations in the germline are associated with hypochondroplasia or other dysplasias in children $(37,38)$. Further knowledge on the subject is warranted; however, it is possible that, in the rare cases of childhood cancer with FGFR3 mutations, as well as childhood cancer cases without FGFR3 or PIK3CA mutations, targeted FGFR therapy could be of use. Directed therapy against FGFR, in patients and in vitro, alone and in combination with other drugs (i.e., PI3K inhibitors), has been studied more extensively in other types of cancer, particularly bladder cancer, and can also be effective in cells without FGFR or PIK3CA mutations (39-43). The synergistic effects of FGFR and mTOR kinase inhibitors have been observed following in vitro testing of ovarian cancer cell lines (44). This approach could also help avoid the development of resistance that has been reported following the use of a single drug $(40,41)$.

In the present study, the use of FGFR and PI3K inhibitors alone and in combination was investigated on $5 \mathrm{NB}$ cell lines, SK-N-AS, SK-N-BE(2)-C, SK-N-DZ, SK-N-FI and SK-N-SH. In the growth inhibition assays, SK-N-SH was exceptionally sensitive to AZD4547, but also somewhat sensitive to both PI3K inhibitors, while the SK-N-BE(2)-C and SK-N-DZ cells were less sensitive to AZD4547, but still sensitive to both PI3K inhibitors. The SK-N-FI and SK-N-AS cells were generally less sensitive to both inhibitors than the other 3 cell lines, but did in fact show some sensitivity to BEZ235. All cell lines were considerably more sensitive to AZD4547 and BEZ235 combination treatments.

The overall sensitivity of SK-N-SH to both inhibitors has no simple explanation, although it is noteworthy that this cell line has a neuroblastoma ras viral oncogene homolog missense mutation (https://depmap.org/portal/). Its sensitivity could not be attributed to the presence of $M Y C N$ amplifications, since SK-N-SH did not have such amplifications. Nevertheless, the SK-N-SH cell line is generally less chemoresistant than the other cell lines included in this study, possibly due to its higher differentiation status. However, MYCN amplifications were present in the SK-N-DZ and SK-N-BE(2)-C (https://depmap.org/portal/) cells, which may explain their sensitivity to BEZ235, which also inhibits mTOR kinases. It has namely, previously been reported that the inhibition of mTOR-kinase destabilizes MYCN and could be used as a potential treatment for MYCN-dependent tumors (16). This is important, particularly for SK-N-BE(2)-C, which has been shown to have a marked insensitivity to doxorubicin (28). However, the development of resistance against targeted therapy that has been reported when using one drug alone may be combated by using two drugs in combination (44).

In the present study, the SK-N-FI and SK-N-AS cells were markedly resistant to the FGFR inhibitor, AZD4547, and were not particularly sensitive to the PI3K inhibitors, BEZ235 and BKM120, either. However, similar to all other cell lines, they were more sensitive to the combination of AZD4547 and BEZ235. The combination of AZD4547 and BEZ235 induced additive or synergistic effects in 38/40 tested dose combinations in the 5 tested NB cell lines; no combination had a significantly weaker effect on viability than the single drugs alone. The two antagonistic combinations need to be further investigated in order to understand their relevance; both involved a high concentration of BEZ235, which induced a great effect on its own. The positive combinational effects again emphasized the possible benefit of using the two drugs simultaneously in severe cases of NB, where the use of one drug alone is not sufficient to cause abrogation of tumor growth.

To the best of our knowledge, this is the first time that drugs against FGFR and PI3K were used in combination for the treatment of NB cell lines, although the use of PI3K inhibitors has been documented previously in NB cell lines with favorable effects (16). When comparing the concentrations of the PI3K and FGFR inhibitors used herein on the NB cell lines to those previously used on urinary bladder cell lines, the drug concentrations of the PI3K inhibitors were relatively, but not completely, similar, but those of the FGFR inhibitor AZD4547 were higher (42). It is possible that cell lines with FGFR or PI3K mutations could require lower drug concentrations, and such cell lines remain to be tested. Nevertheless, it has been reported 
that the presence of $P I 3 K$ mutations does not always affect drug sensitivity (45). PI3K mutations have, however, been reported to affect sensitivity to FGFR inhibitors used to combat cervical tumors with FGFR3-TACC3-fusion genes, and the authors therefore suggested the use of combination treatments (46).

The present study had its limitations, since only 29 NBs and $5 \mathrm{NB}$ cell lines were examined. However, one FGFR3 mutation was identified in $1 / 29 \mathrm{NBs}$, indicating that this is not a frequent event, but still a viable possibility in a minority of NB cases, and could be followed up in situations where the patient does not respond to treatment. Furthermore, although only 5 NB lines were used, they are representative of the types of cell lines frequently used in the scientific community $(24-28,47)$. This also applies to the methodologies used herein. In addition, the assays used in the present study resulted in concordant findings and indicated that SK-N-SH was the most sensitive cell line to all treatments, while SK-N-FI was the most resistant one. The remaining cell lines showed variable responses, possibly due to the genetic setting of these cell lines, i.e. the presence of amplified $M Y C N$. In the future, NB lines with FGFR mutations may be of use to experimentally test it they are more sensitive to FGFR and PI3K targeted therapy, which has been indicated in some, but not all, conditions (45).

In conclusion, FGFR3 mutations are uncommon, but present in NBs. Upon treatment of 5 NB cell lines with either FGFR and PI3K inhibitors alone, a decrease in viability and proliferation was observed in most cell lines. However, upon combination treatment with both types of drugs (AZD4547 and BEZ235) the sensitivity of all cell lines increased considerably, which may provide a possible therapeutic strategy for chemotherapy-resistant NBs.

\section{Acknowledgements}

The authors would like to thank Associate Professor Bertha Brodin, Karolinska Institute, for her assistance and the possibility to perform the proliferation assays by providing the xCELLigence machine.

\section{Funding}

This study was supported by the Swedish Childhood Cancer Fond (PR2017-0042, PR2017-0052), the Swedish Cancer Society (180440, 2017/658), the Stockholm Cancer Society (181053), the Swedish Cancer and Allergy Foundation (190), the Royal Swedish Academy of Sciences (2017-2018), the Stockholm City Council (20180037), the Magnus Bergvall Foundation (2018-02683), the Märta and Gunnar V Philipson Foundation (2018) and the Karolinska Institutet of Sweden (2018:0007), Lindhés Advokatbyrå (LA2019-0080).

\section{Availability of data and materials}

The datasets used and/or analyzed during the current study are available from the corresponding author on reasonable request.

\section{Authors' contributions}

ONK and SH, performed the majority of the experiments, interpreted the data, calculated the statistics and contributed to the writing of the manuscript. BKAL collaborated with ONK and $\mathrm{SH}$ in performing some experiments and in the writing of the manuscript. AO initiated the experiments, interpreted the initial experiments and contributed to the writing of the Materials and methods section, all under the supervision of $\mathrm{CB}$, who also planned the initial experiments and performed the CAST-PCR. TA collaborated with SH and ONK, performed the western blot analysis experiment and contributed with $\mathrm{SH}$ and ONK to the writing of the manuscript. MW assisted the authors in planning some experiments, performed combinational analyses, and assisted in the final interpretation and presentation of the data and the writing and statistics of the manuscript. TD made substantial contributions to the conception and design, acquisition of the data, analysis and interpretation of the data, and was involved in the drafting of the manuscript and revising it critically for important intellectual content. All authors have agreed to be accountable for all aspects of the work in ensuring that questions related to the accuracy and integrity of any part of the work are appropriately investigated and resolved. All authors have critically read and approved the manuscript.

\section{Ethics approval and consent to participate}

With regard to patient information, the study was approved by the Ethical Committee of the Karolinska Institutet (Stockholm, Sweden; approval nos. 2009/1369-31/1, 2007/1253-31/3 and 2003/736). Informed consent for the use of tumor samples in research was provided by the parents/guardians. In accordance with the approval from the Ethics Committee the informed consent was either written or verbal. When verbal or written assent was not obtained the decision was documented in the medical record.

\section{Patient consent for publication}

Not applicable.

\section{Competing interests}

The authors declare that they have no competing interests.

\section{References}

1. Wesche J, Haglund K and Haugsten EM: Fibroblast growth factors and their receptors in cancer. Biochem J 437: 199-213, 2011.

2. Parker BC, Engels M, Annala M and Zhang W: Emergence of FGFR family gene fusions as therapeutic targets in a wide spectrum of solid tumours. J Pathol 232: 4-15, 2014.

3. Testa U, Castelli G and Pelosi E: Lung cancers: Molecular characterization, clonal heterogeneity and evolution, and cancer stem cells. Cancers (Basel) 10: E248, 2018.

4. Meric-Bernstam F, Frampton GM, Ferrer-Lozano J, Yelensky R, Pérez-Fidalgo JA, Wang Y, Palmer GA, Ross JS, Miller VA, $\mathrm{Su} \mathrm{X}$, et al: Concordance of genomic alterations between primary and recurrent breast cancer. Mol Cancer Ther 13: 1382-1389, 2014.

5. Bersani C, Sivars L, Haeggblom L, DiLorenzo S, Mints M, Ahrlund-Richter A, Tertipis N, Munck-Wikland E, Näsman A, Ramqvist $\mathrm{T}$ and Dalianis $\mathrm{T}$ : Targeted sequencing of tonsillar and base of tongue cancer and human papillomavirus positive unknown primary of the head and neck reveals prognostic effects of mutated FGFR3. Oncotarget 8: 35339-35350, 2017. 
6. Taylor JG VI, Cheuk AT, Tsang PS, Chung JY, Song YK, Desai K, Yu Y, Chen QR, Shah K, Youngblood V, et al: Identification of FGFR4-activating mutations in human rhabdomyosarcomas that promote metastasis in xenotransplanted models. J Clin Invest 119: 3395-3407, 2009

7. Lehtinen B, Raita A, Kesseli J, Annala M, Nordfors K, Yli-Harja O, Zhang W, Visakorpi T, Nykter M, Haapasalo H and Granberg KJ: Clinical association analysis of ependymomas and pilocytic astrocytomas reveals elevated FGFR 3 and FGFR1 expression in aggressive ependymomas. BMC Cancer 17: 310, 2017.

8. Parker BC, Annala MJ, Cogdell DE, Granberg KJ, Sun Y, Ji P, Li X, Gumin J, Zheng H, Hu L, et al: The tumorigenic FGFR3-TACC3 gene fusion escapes miR-99a regulation in glioblastoma. J Clin Invest 123: 855-865, 2013.

9. Agelopoulos K, Richter GH, Schmidt E, Dirksen U, von Heyking K, Moser B, Klein HU, Kontny U, Dugas M, Poos $\mathrm{K}$, et al: Deep sequencing in conjunction with expression and functional analyses reveals activation of FGFR1 in ewing sarcoma. Clin Cancer Res 21: 4935-4946, 2015.

10. Gallia GL, Rand V, Siu IM, Eberhart CG, James CD, Marie SK Oba-Shinjo SM, Carlotti CG, Caballero OL, Simpson AJ, et al: PIK3CA gene mutations in pediatric and adult glioblastoma multiforme. Mol Cancer Res 4: 709-714, 2006.

11. Grill J, Puget S, Andreiuolo F, Philippe C, MacConaill L and Kieran MW: Critical oncogenic mutations in newly diagnosed pediatric diffuse intrinsic pontine glioma. Pediatr Blood Cancer 58: 489-491, 2012.

12. Shukla N, Ameur N, Yilmaz I, Nafa K, Lau CY, Marchetti A, Borsu L, Barr FG and Ladanyi M: Oncogene mutation profiling of pediatric solid tumors reveals significant subsets of embryonal rhabdomyosarcoma and neuroblastoma with mutated genes in growth signaling pathways. Clin Cancer Res 18: 748-757, 2012.

13. Dam V, Morgan BT, Mazanek P and Hogarty MD: Mutations in PIK3CA are infrequent in neuroblastoma. BMC Cancer 6: 177, 2006.

14. Izycka-Swieszewska E, Brzeskwiniewicz M, Wozniak A, Drozynska E, Grajkowska W, Perek D, Balcerska A, Klepacka T and Limon J: EGFR, PIK3CA and PTEN gene status and their protein product expression in neuroblastic tumours. Folia Neuropathol 48: 238-245, 2010.

15. Opel D, Poremba C, Simon T, Debatin KM and Fulda S: Activation of Akt predicts poor outcome in neuroblastoma. Cancer Res 67: 735-745, 2007.

16. Vaughan L, Clarke PA, Barker K, Chanthery Y, Gustafson CW, Tucker E, Renshaw J, Raynaud F, Li X, Burke R, et al: Inhibition of mTOR-kinase destabilizes MYCN and is a potential therapy for MYCN-dependent tumors. Oncotarget 7: 57525-57544, 2016.

17. Chesler L, Schlieve C, Goldenberg DD, Kenney A, Kim G McMillan A, Matthay KK, Rowitch D and Weiss WA: Inhibition of phosphatidylinositol 3-kinase destabilizes Mycn protein and blocks malignant progression in neuroblastoma. Cancer Res 66 : 8139-8146, 2006.

18. Segerström L, Baryawno N, Sveinbjörnsson B, Wickström M Elfman L, Kogner P and Johnsen JI: Effects of small molecule inhibitors of PI3K/Akt/mTOR signaling on neuroblastoma growth in vitro and in vivo. Int J Cancer 129 : 2958-2965, 2011.

19. Klempner SJ, Myers AP and Cantley LC: What a tangled web we weave: Emerging resistance mechanisms to inhibition of the phosphoinositide 3-kinase pathway. Cancer Discov 3: 1345-1354 2013.

20. Maris JM: Recent advances in neuroblastoma. N Engl J Med 362: 2202-2211, 2010.

21. Brodeur GM: Neuroblastoma: Biological insights into a clinical enigma. Nat Rev Cancer 3: 203-216, 2003.

22. Giraud G, Ramqvist T, Pastrana DV, Pavot V, Lindau C, Kogner P, Orrego A, Buck CB, Allander T, Holm S, et al: DNA from KI, WU and Merkel cell polyomaviruses is not detected in childhood central nervous system tumours or neuroblastomas. PLoS One 4 e8239, 2009

23. Kocak H, Ackermann S, Hero B, Kahlert Y, Oberthuer A, Juraeva D, Roels F, Theissen J, Westermann F, Deubzer H, et al: Hox-C9 activates the intrinsic pathway of apoptosis and is associated with spontaneous regression in neuroblastoma. Cell Death Dis 4: e586, 2013.

24. Biedler JL, Helson L and Spengler BA: Morphology and growth, tumorigenicity, and cytogenetics of human neuroblastoma cells in continuous culture. Cancer Res 33: 2643-2652, 1973.
25. Biedler JL and Spengler BA: A novel chromosome abnormality in human neuroblastoma and antifolate-resistant Chines hamster cell lives in culture. J Natl Cancer Inst 57: 683-695, 1976.

26. Sugimoto T, Tatsumi E, Kemshead JT, Helson L, Green AA and Minowada J: Determination of cell surface membrane antigens common to both human neuroblastoma and leukemia-lymphoma cell lines by a panel of 38 monoclonal antibodies. J Natl Cancer Inst 73: 51-57, 1984

27. Helson L and Helson C: Human neuroblastoma cells and 13-cis-retinoic acid. J Neurooncol 3: 39-41, 1985.

28. LaQuaglia MP, Kopp EB, Spengler BA, Meyers MB and Biedler JL: Multidrug resistance in human neuroblastoma cells. J Pediatr Surg 26: 1107-1112, 1991.

29. Carén H, Kryh H, Nethander M, Sjöberg RM, Träger C, Nilsson S, Abrahamsson J, Kogner P and Martinsson T: High-risk neuroblastoma tumors with 11q-deletion display a poor prognostic, chromosome instability phenotype with later onset. Proc Natl Acad Sci USA 107: 4323-4328, 2010.

30. Kryh H, Carén H, Erichsen J, Sjöberg RM, Abrahamsson J, Kogner P and Martinsson T: Comprehensive SNP array study of frequently used neuroblastoma cell lines; copy neutral loss of heterozygosity is common in the cell lines but uncommon in primary tumors. BMC Genomics 12: 443, 2011.

31. Helson C, Zahn Z and Helson L: Reversion of p-glycoprotein mediated multidrug-resistance to vincristine and adriamycin by psc-833, a cyclosporine derivative in human neuroblastoma cell-lines. Int J Oncol 5: 1037-1042, 1994.

32. Bersani C, Haeggblom H, Ursu RG, Giusca SE, Marklund L, Ramqvist T, Näsman A and Dalianis T: Overexpression of FGFR 3 in HPV-positive tonsillar and base of tongue cancer is correlated to outcome. Anticancer Res 38: 4683-4690, 2018.

33. Holzhauser S, Kostopoulou ON, Ohmayer A, Lange BKA, Ramqvist T, Andonova T, Bersani $\mathrm{C}$, Wickström $\mathrm{M}$ and Dalianis T: Antitumor effects in vitro of FGFR and PI3K inhibitors on human papillomavirus positive and negative tonsillar and base of tongue cancer. Oncol Lett (In press).

34. Foucquier J and Guedj M: Analysis of drug combinations: Current methodological landscape. Pharmacol Res Perspect 3: e00149, 2015

35. Chou TC: Drug combination studies and their synergy quantification using the Chou-Talalay method. Cancer Res 70: 440-446, 2010.

36. Patani H, Bunney TD, Thiyagarajan N, Norman RA, Ogg D, Breed J, Ashford P, Potterton A, Edwards M, Williams SV, et al: Landscape of activating cancer mutations in FGFR kinases and their differential responses to inhibitors in clinical use. Oncotarget 7: 24252-24268, 2016.

37. Arenas MA, Del Pino M and Fano V: FGFR3-related hypochondroplasia: Longitudinal growth in 57 children with the p.Asn540Lys mutation. J Pediatr Endocrinol Metab 31: 1279-1284, 2018

38. Chen J, Yang J, Zhao S, Ying H, Li G and Xu C: Identification of a novel mutation in the FGFR3 gene in a Chinese family with Hypochondroplasia. Gene 641: 355-360, 2018.

39. Wang L, Šuštić T, Leite de Oliveira R, Lieftink C, Halonen P, van de Ven M, Beijersbergen RL, van den Heuvel MM, Bernards R and van der Heijden MS: A functional genetic screen identifies the phosphinositide 3-kinase pathway as a determinant of resistance to fibroblast grown factor receptor inhibitors in FGFR mutant urothelial cell carcinoma. Eur Urol 71: 858-862, 2017.

40. Wang J, Mikse O, Liao RG, Li Y, Tan L, Janne PA, Gray NS, Wong KK and Hammerman PS: Ligand-associated ERBB2/3 activation confers acquired resistance to FGFR inhibition in FGFR3-dependent cancer cells. Oncogene 34: 2167-2177, 2015.

41. Herrera-Abreu MT, Pearson A, Campbell J, Shnyder SD Knowles MA, Ashworth A and Turner NC: Parallel RNA interference screens identify EGFR activation as an escape mechanism in FGFR3-mutant cancer. Cancer Discov 3 : 1058-1071, 2013.

42. Brands RC, Knierim LM, De Donno F, Steinacker V, Hartmann S, Seher A, Kübler AC and Müller-Richter UDA: Targeting VEGFR and FGFR in head and neck squamous cell carcinoma in vitro. Oncol Rep 38: 1877-1885, 2017.

43. Singleton KR, Hinz TK, Kleczko EK, Marek LA, Kwak J, Harp T, Kim J, Tan AC and Heasley LE: Kinome RNAi screens reveal synergistic targeting of MTOR and FGFR1 pathways for treatment of lung cancer and HNSCC. Cancer Res 75: 4398-4406, 2015 . 
44. Cai W, Song B and Ai H: Combined inhibition of FGFR and mTOR pathways is effective in suppressing ovarian cancer. Am J Transl Res 11: 1616-1625, 2019.

45. Munster P, Aggarwal R, Hong D, Schellens JH, van der Noll R, Specht J, Witteveen PO, Werner TL, Dees EC, Bergsland E, et al: First-in-human phase I study of GSK2126458, an oral pan-class I phosphatidylinositol-3-kinase inhibitor, in patients with advanced solid tumor malignancies. Clin Cancer Res 22: 1932-1939, 2016.
46. Tamura R, Yoshihara K, Saito T, Ishimura R, MartínezLedesma JE, Xin H, Ishiguro T, Mori Y, Yamawaki K, Suda K, et al: Novel therapeutic strategy for cervical cancer harboring FGFR3-TACC3 fusions. Oncogenesis 7: 4, 2018.

47. Zheng X, Naiditch J, Czurylo M, Jie C, Lautz T, Clark S, Jafari N, Qiu Y, Chu F and Madonna MB: Differential effect of long-term drug selection with doxorubicin and vorinostat on neuroblastoma cells with cancer stem cell characteristics. Cell Death Dis 4: e740, 2013. 